Article

\title{
On Recursive Modification in Child L1 French
}

\author{
Yves Roberge ${ }^{1, *}$, Ana Teresa Pérez-Leroux ${ }^{2,3}$ and Anna Frolova 1 \\ 1 Department of French Studies, University of Toronto, 50 St Joseph Street, Toronto, ON M5S 1J4, Canada; \\ anna.frolova@utoronto.ca \\ 2 Department of Spanish and Portuguese, Victoria College, University of Toronto, 91 Charles Street West, \\ Toronto, ON M5S 1K5, Canada; at.perez.leroux@utoronto.ca \\ 3 Cognitive Science Program, University of Toronto, 100 St. George Street, Toronto, ON M5S 3G3, Canada \\ * Correspondence: yves.roberge@utoronto.ca; Tel.: +1-647-459-5202
}

Received: 23 December 2017; Accepted: 5 March 2018; Published: 16 March 2018

\begin{abstract}
This paper investigates nominal recursive modification (RM) in the L1 acquisition of French. Although recursion is considered the fundamental property of human languages, recursive self-embedding is found to be difficult for children in a variety of languages and constructions. Despite these challenges, the acquisition of RM proves to be resilient; acquirable even under severely degraded input conditions. From a minimalist perspective on the operations of narrow syntax, recursive embedding is essentially the application of a sequence of Merge operations (Chomsky 1995; Trotzke and Zwart 2014); therefore, given the universality of Merge, we do not expect to find cross-linguistic differences in how difficult recursion is. But if the challenging nature of recursion stems from factors which might differ from language to language, we expect different outcomes cross-linguistically. We compare new data from French to existing English data (Pérez-Leroux et al. 2012) in order to examine to what extent language-specific properties of RM structures determine the acquisition path. While children's production differs significantly from their adult's counterparts, we find no differences between French-speaking and English-speaking children. Our findings suggest that the challenging nature of recursion does not stem from the grammar itself and that what shapes the acquisition path is the interaction between universal properties of language and considerations not specific to language, namely computational efficiency.
\end{abstract}

Keywords: recursion; complexity; Determiner Phrases; Noun Phrase modification; L1 acquisition; French syntax; minimalism

\section{Introduction}

Although recursion as an abstract property is considered a fundamental feature of human languages, recursive self-embedding, as in (1), has been shown to be difficult for children in a variety of languages and constructions.

1. Mary's mother's friend's dog ran away.

In child English, recursive possessive and Prepositional Phrase (PP) structures are rare in production, and difficult to understand (Limbach and Adone 2010; Roeper 2011; Pérez-Leroux et al. 2012). Despite these challenges, the acquisition of recursive modification (RM) proves to be resilient, and acquirable even under severely degraded input conditions, such as in deaf home signers (Goldin-Meadow 1982) and bilinguals (Pérez-Leroux et al. 2017). The structures that can function recursively vary across different languages, fueling the controversy regarding the universality of recursion (Evans and Levinson 2009).

From a minimalist perspective on the operations of narrow syntax, recursive embedding is essentially the application of a sequence of Merge operations (Chomsky 1995; Trotzke and Zwart 2014) thereby raising the general research question: Why is RM challenging in L1 acquisition? In other words, why do children need time to apply Merge in a recursive manner? 
To address this question, we compare new data from French to existing English data (Pérez-Leroux et al. 2012) in order to examine to what extent the acquisition path is determined by language-specific properties of RM structures. Our specific research questions are:

I. What are the main patterns of production of complex Noun Phrases (NPs) in French-speaking children compared to French-speaking adults?

II. Do French-speaking children have a general advantage over English-speaking children in terms of their production of recursive NPs?

III. Do French-speaking children have an initial advantage?

IV. Do French-speaking children have an advantage with recursive possessives, given that in English, a generally right-branching language, possession is primarily expressed via a left-branching strategy, the Saxon genitive '-'s'?

Section 2 provides the larger context, on recursion, French NPs, and their acquisition as well as our hypotheses, for the study reported on in the subsequent sections.

\section{Background}

\subsection{Recursivity and Complexity in Language Acquisition}

When addressing the question of how children's utterances increase in complexity with age, the issue of determining what is complex naturally arises. Although researchers do not all agree on its nature (McWhorter 2011; Culicover 2013; Newmeyer and Preston 2014; Roeper and Speas 2014; Trotzke and Bayer 2015), they mostly agree that embedding, including self-embedding, increases complexity (Culicover and Jackendoff 2006; Givón 2009). Watumull et al. (2014) state that "the grammars of all natural languages are recursive" (p. 1) and that syntactic constituents are built recursively "in a stepwise strongly generative process creating increasing complexity" (p. 6). Recursive structures are the result of repeated applications of Merge operations and it follows that structures built through similar derivational steps should all be similarly complex. In other words, given the architectural and universal nature of recursion, any cap on recursion that might be observed in output structures whether in children or adults must be attributable to arbitrary external factors. We follow the general approach outlined in Bejar et al. (forthcoming) according to which "because recursive iterations of Merge can result in different varieties of recursively embedded output structures, some structural elaborations [may] turn out to be more complex than others."

If the challenge of recursion lies in the narrow syntax operations involved in the derivation of phrases and sentences, i.e., with applications of Merge, then we expect recursive structures to be equally complex across languages with comparable constructions. Stated differently, given the universality of Merge, we do not expect to find cross-linguistic differences in how difficult recursion is for children. This is our Null Hypothesis, which predicts that there should be no relevant differences between languages in the $\mathrm{L} 1$ acquisition process.

If, on the other hand, the challenging nature of recursion stems from factors which might differ from language to language (e.g., properties of specific lexical items or differences in constructions), then we expect different developmental outcomes across languages. This Alternative Hypothesis makes the prediction that the observed difficulties will differ between languages. In the present study, this Alternative Hypothesis is explored in the context of two properties where English and French NPs differ: uniformity of branching directionality in nominal modification, and the kinds of strategies allowed to embed nominal modifiers (relativization, prepositional modification are present in both, but only English relies on case morphology for possession). We will return to this in our presentation of hypotheses. 


\subsection{French Determiner Phrases}

Turning now to our empirical domain, there is essentially no published work dealing in any relevant detail with modification of N by PPs in French. Previous research is mainly concerned with the semantics of French prepositions ((Vandeloise 1991) for instance) and complements in 'à 'to' and de 'of' ((Godard 1988; Abeillé et al. 2003) for instance). For this reason, we provide a basic description of the structures at stake.

Simple Determiner Phrases (DP) in French are structured as follows:

2. [DP D [NP N ]]

For our present purpose, the fine-grained functional architecture within and above NP does not matter; what is of interest is the potential expansion of the structure through embedding, typically used to restrict the description of the set denoted by the head Noun. Two possibilities arise: complementation as in (3), where the complement is semantically selected by N, or adjunction as in (4), where the added constituent simply modifies the head Noun.

3. $\mathrm{L}^{\prime}$

$\begin{array}{llll}\mathrm{L}^{\prime} & \text { auteur } & \text { de } & \text { ce roman } \\ \text { the } & \text { author } & \text { of } & \text { this novel } \\ \left.\text { [DP [D }{ }^{\prime}\right] & \text { [NP [N auteur } & \text { [PP [P de] } & \text { [DP ce roman]]] }\end{array}$

'The author of this novel.'

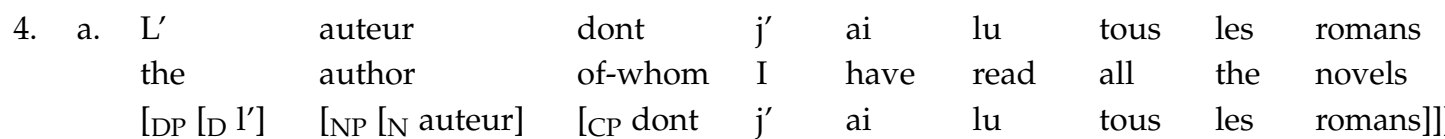
'The author of-whom I have read all the novels.'

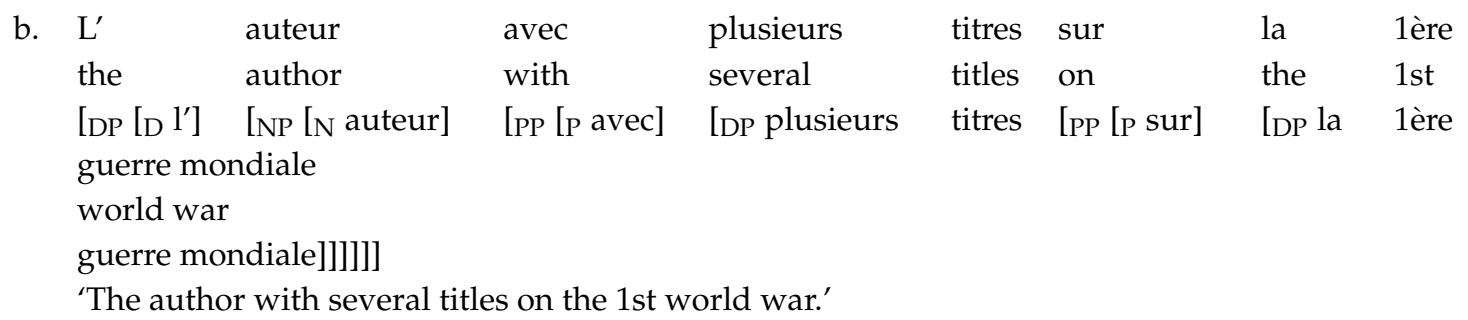

Crucially, the number of modifiers is potentially unlimited:

5. Un auteur avec plusieurs titres sur les soldats qui ont combattu dans les tranchées près de Passendale vers la fin de la lère guerre mondiale...

An author with several titles on the soldiers who have fought in the trench near Passchendaele towards the end of the 1st world war...

Our study is restricted to DPs that include PP modifiers (not complements). In terms of the internal structure of the expanded DP, we must distinguish between recursive multiple modification and sequential multiple modification. In the first case, each nominal added to the DP modifies the noun immediately dominating it (6), while in the other they all modify the head Noun (7).

6. La personne avec un bébé dans une poussette the person with a baby in a stroller [DP [D la] [NP [N personne] [PP [P avec] [DP un bébé [PP [P dans ] [DP une poussette ]]]]] 'The person with a baby in a stroller' 


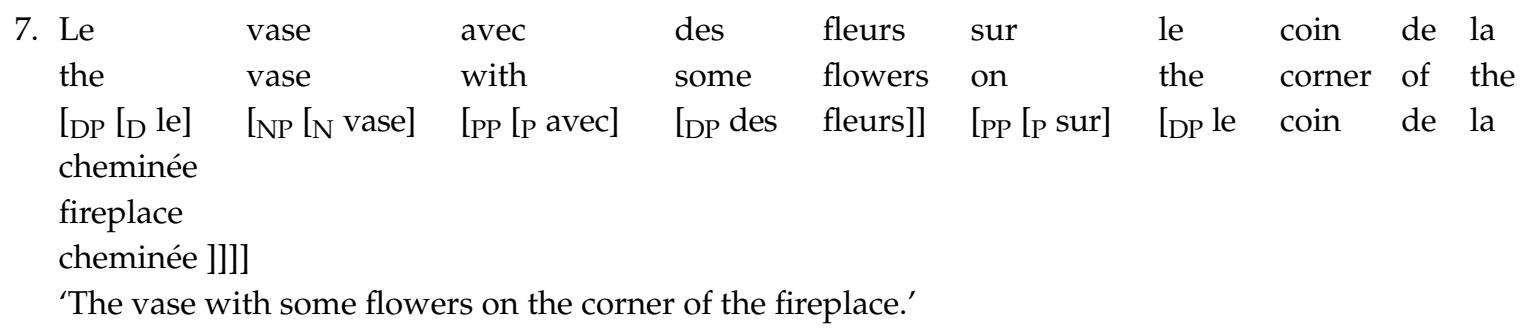

Note that (6) and (7) are ambiguous when taken in isolation but a context would serve to disambiguate them. A variety of prepositions are allowed to embed DP internal modifiers (avec 'with', sur 'on', etc.), but the polysemous prepositions $d e$ 'of' and à 'to' are very common and srve to establish different semantic relations, including purpose (table à manger 'dining table'), theme (peinture de fleurs 'painting of flowers'), kinship (soeur d'Elmo 'sister of Elmo'), ownership (le sac de la fille 'the bag of the girl'), etc. Since the focus of this paper is on doubly modified DPs, we will use the terms sequential double modification (SDM) and recursive double modification (RDM).

\subsection{The Acquisition of Determiner Phrase Structure in Child French}

The acquisition of the DP in child French has been described as a gradual process (Pannemann 2007; Bassano et al. 2008). According to Pannemann (2007), DP-internal elements emerge in the following order: bare nouns $>$ determiner with nouns $>$ pre-nominal adjectives $>$ post-nominal adjectives. At the initial stage thus, nominal structures consist primarily of bare nouns; and article use is optional (Prévost 2009). By two and a half years, determiners are systematically present. In the work presented in Demuth and Tremblay (2008), young French-speaking children employed determiners at one year and a half, and they produced more than $82 \%$ of determiners between the ages of $2 ; 3$ to $2 ; 5$. Errors in DP production are common and include determiner omission, gender and number agreement, and overuse of definite articles (Clark 1986; Frechette and Labelle 2007; Pannemann 2007; Bassano et al. 2008; Demuth and Tremblay 2008; Prévost 2009). These errors persist longer with more complex structures, according to Royle and Valois (2010).

By age three, children already employ a range of determiners regularly. In data from the spontaneous speech of 60 children aged from one year and six months $(1 ; 6)$ to 3;4, Bassano et al. (2008) identified many types of determiners, including indefinite (un gâteau 'a cake') and definite articles (le chat 'the cat'), possessive (mon, ma 'my', leur 'their'), demonstrative adjectives (ce, cette 'this'; ces 'these') and other types of determiners, such as numeral (deux 'two', trois 'three'), interrogative (quelle 'which'), and indefinite (plusieurs 'many, several', autre 'other', même 'same', tout/toute/tous 'whole, all'). However, possessives, demonstrative adjectives, and other determiners remained rare (approximately 10\% for possessives, and less than one percent for other types). In addition, Bassano et al. (2008) reported an increase in contrastive uses of a given noun without determiner or with different determiners between ages $1 ; 8$ and 3;3.

The production of modified DP increases between ages three and five, but remains low in relation to the production of simple DPs. Royle and Stine (2012) compared SLI children to typically developing MLU-matched children (mean age 3;9; range 3;2-4;8) and age-matched children (mean age 5;6; range $4 ; 10-5 ; 11$ ). They classified DPs as simple if they consisted of common noun and determiner (un chien 'a dog') or proper nouns (grandpapa Gilles 'grandpa Gilles'), or N plus P (d'place 'of room'). Complex DPs included a noun with a determiner and an adjective (un bouchon vert 'a green plug'), a noun with a determiner and a prepositional phrase (les arbres (dans les arbres) dans les branches 'the trees (in the trees) in the branches'), and an adjective with an omitted noun (la rouge 'the red (one)'). Royle and Stine (2012) found that even within this age range, most production consisted of simple DPs (78\% for the younger group, and 70\% for the older children). Older children were fully productive with the various types of complex DPs, mostly with adjectives. PP modification made up 3\% and 5\% of the production of younger and older children, respectively. 
According to Pannemann (2007), children start to use pre-nominal adjectives at 1;8 (mean age of first use $=23$ months) but post-nominal adjectives emerge a few months later (mean age of first use $=25$ months). Valois and Royle (2009) reported that DPs overtly containing a determiner, a noun, and an adjective appear in spontaneous production between ages 2;1-2;4 but are rare (less than $1 \%$ of all occurrences of DPs). Royle and Valois (2010) examined the acquisition of colour and size adjectives by francophone children from 3;1 to 4;11 years in a puzzle-based elicited production study. Even the youngest children used adjective-modified DPs, and they observed an increasing ability with age to produce appropriate adjectives. One of the elicitation conditions targeted combinations of size and colour adjectives (i.e., la grosse maison blanche 'the big white house'). By 3;5 such doubly modified adjectival structures were used at $80 \%$, and the rate increased to $90 \%$ at $3 ; 6$.

The first possessive constructions are attested around age two. Interestingly, these primarily take the form of non-target analytic structures that include a preposition ( $\grave{a}$ or $d e$ ) and a pronoun instead of the target possessive determiners, which appear at a later age (Clark 1986; Aimard 1996), as in (8):

8. la cuiller de moi

the spoon of me (instead of ma cuiller 'my spoon')

'my spoon'

$(1 ; 11)(C l a r k 1986$, p. 730)

Children also produce target-like instance of DPs with possession, such as (9) below, where the object of the preposition is lexical.

9. $\mathrm{c}^{\prime}$ est la maman du lapin

it is the mother of+the rabbit

'this is rabbit's mom' (Age not provided) (Bassano et al. 2008, p. 420)

Relativization appears early in the spontaneous speech of two-year-old francophone children, initially in the form of cleft constructions:

10. $c^{\prime}$ est ça qui va là

it is that that goes there

'It's that that goes there.'

(2;0) (Labelle 1990, p. 113)

After three-and-a-half, relative clauses (RC) are regularly used; however, the acquisition of RCs is a long process. Developmental patterns include incorrect choices of relative pronouns (11) and frequent use of resumptive elements (12), all of which continue to be attested after 6 years (Clark 1986; Labelle 1990; Fragman 1998; Belzil 2004):

11. la voiture que le monsieur met une roue the car that the man puts a wheel

'The car that the man is putting a wheel.' $\quad$ (5;06; Bouvier and Platone 1976; cited in Clark 1986)

12. sur la balle $\mathrm{qu}^{\prime}$ il lance la balle

on the ball that he throws the ball

'On the ball that he throws the ball.'

(5;0) (Labelle 1990, p. 100)

Furthermore, even the RCs of school-aged French children show less diversity of forms and uses (Jisa and Kern 1998).

In sum, the various analyses show a consistent picture in French. DP structures develop in the following sequence:

13. Developmental sequence for French DPs

bare nouns $>\operatorname{det}+$ nouns $>$ Adj+N $>N+A d j>N+P P s ~>N+R C$ modifiers 
DPs containing one level modification (both PPs and RCs) emerge in two-year-olds, and are already established in three-year-olds. However, as observed in other languages (Eisenberg et al. 2008; Pérez-Leroux et al. forthcoming), nominal modification is less productive and structurally more limited in children compared to adults, even across the school years. One noteworthy characteristic of French acquisition is that children start out with the more structurally elaborated expression of possession (as PPs) rather than the simple determiner option. Although we have seen that, by the age of four, children can productively modify a noun with two adjectives, to the best of our knowledge, no previous work has examined RM in DPs in the acquisition of French.

\subsection{Hypotheses}

French and English DPs share many characteristics. The French structures above would work equally well to describe English DPs, with one exception: the existence of the left-branching possessor construction in English, the Saxon genitive '-'s' as in (1)-Mary's mother's friend's dog ran away. In French, only a right-branching structure serves to embed possessor DPs, as shown in (14).

14. Le chien de $l^{\prime}$ ami de la mère de Marie $s^{\prime}$ est sauvé the dog of the friend of the mother of Mary REFL is saved 'Mary's mother's friend's dog ran away.'

If we consider then that the French DP appears to be uniformly right-branching, whereas English includes a productive, and very common, left branching structure, it is clear the input in French is more consistent. As pointed out by a reviewer though, the presence of prenominal adjectives in the French input introduces the possibility of left-branching modification. However, recursivity is what is at stake in our study and although single adjectives can appear preverbally, descriptively speaking recursion is mostly found in postnominal adjectives in French (Roeper and Snyder 2004). In addition, according to Laenzlinger (2005, p. 686) "all adjectives are postnominal at some step of the derivation. Prenominalization of adjectives is obtained through subsequent AdjP movement to a specific functional projection within the determiner domain." Consequently, we maintain that French is uniformly right-branching in the nominal domain. Returning to our research questions and hypotheses, given the centrality of input in the language acquisition process, it could be assumed that the uniformity of the input might translate as an advantage for French children and that this would come up in our results as either: (i) an initial advantage; (ii) faster development, which can be attested globally (for all forms of recursive modification); or (iii) locally (i.e., limited to possession conditions). According to Culicover (2013, p. 328), "complexity of processing is correlated with memory load, and uniformity of branching reduces memory load [ ... ] uniformity is computationally less complex". From the English perspective therefore, mixed directionality might introduce an early cost that becomes apparent only in the performance of younger children.

Another potentially relevant difference between English and French involves a contrast in the choice of linking strategies for modifiers within DPs. Again, although no systematic study has examined this in detail, previous works point to a preference in French for modification via relative clauses in contexts where English opts for PPs. Vercollier et al. (2004, p. 241) observe that, contrary to English, French generally requires different strategies to express various modification relations; so, for instance, 'The animals in the zoo are sick' would be said with a relative clause ('that are in the zoo'), an adjective or participle ('kept in the zoo'), or the preposition de ('of the zoo'). Jisa and Kern (1998) note that RCs in French are commonly used to introduce new referents. We return to this in Section 4.2.3.

\section{Materials and Methods}

The method in this study was the same referential elicitation task used in Pérez-Leroux et al. (forthcoming), which was approved by the University of Toronto Office of Research Ethics (protocol reference \#: 27755; approval date: May 2012) and was conducted with 
permission from the school administrators and teachers. Parents were asked to sign a consent letter and to complete a short questionnaire on their children's language history. Children whose parents gave permission were asked if they were willing to participate. At the beginning of the session, they were informed they could take breaks or discontinue the test at any time. Adult participants were recruited among school employees. Recordings were conducted individually in a quiet classroom and lasted between 25 and $40 \mathrm{~min}$. All participants received a small gift. Interviews with participants were recorded by using a digital recorder (ZOOM H4n, Hauppauge, NY, USA) and transcribed for coding. Personal data is kept confidential and is identified by a code rather than a name.

\subsection{Participants}

Our French data were collected in three elementary schools and four daycare centres in Quebec City in May and June 2016 by two researchers. A sample of 78 monolingual French-speaking children aged 4;0 to 6;7 and 12 adult controls participated in the study. Based on information provided by teachers and parents, the participants were monolingual and typically developing children. French-speaking participants were divided into three age groups: four-year-olds $(n=26$, range $3 ; 11-4 ; 11$ years, Mean age $=4 ; 4$, Median $=4 ; 4, S D=2.8$ months $)$, five-year-olds $(n=26$, range $5 ; 1-5 ; 11$ years, Mean age $=5 ; 8$, Median $=5 ; 9, S D=7$ months), and six-year-olds ( $n=26$, range 6;0-6;7 years, Mean age $=6 ; 3$, Median $=6 ; 4, S D=0.7$ months). These speakers were compared to data from the initial English study, where data were collected from 71 English-speaking children and 13 adult controls. In Pérez-Leroux et al. (forthcoming), monolingual typically developing English-speaking children were grouped as four-year-olds ( $n=25$, Mean age $=4 ; 6$, Median $4 ; 6, S D=2.4$ months), five-year-olds ( $n=25$, Mean age $=5 ; 4$, Median $=5 ; 4, S D=3.3$ months $)$, and six-year-olds $(n=21$, Mean age $=6 ; 5$, Median $=6 ; 4, S D=3.2$ months).

\subsection{Stimuli and Procedures}

The original task was developed for English, and subsequently adapted to French by the authors of the present study. The materials targeted production of doubly modified nouns (DPs) with two embedded modifiers. Stimuli included four recursive (RDM) and one non-recursive (SDM) conditions; each condition had between five and seven items. One item was eliminated from the French materials, for a total of 30 test items and 12 distractors. Participants listened to an illustrated story about familiar objects and characters performing simple activities. Each situation had several referents represented on a picture. To properly disambiguate the target referent in answer to the prompt question (which $x$ $\ldots$ ?), the response required multiple modifications. The procedure is illustrated with the recursive comitative condition in (15). Other conditions included recursive locatives (16), recursive possessives (18), and recursive relational nouns (19). As a test of the effect of recursive embedding itself, we included a condition with double non-recursive PPs (Pérez-Leroux et al. forthcoming). As shown in (17), this contained two PPs, which in principle could be structurally ambiguous in the surface, but the visual context determined that the second PP could be attached as modifier to the highest NP. It contained either two locatives (three items) or a mix of locative and comitative PPs (three items). 
15. Recursive comitative condition (RDM)

Prompt question: Lequel des bébés pleure? ('Which baby is crying?')
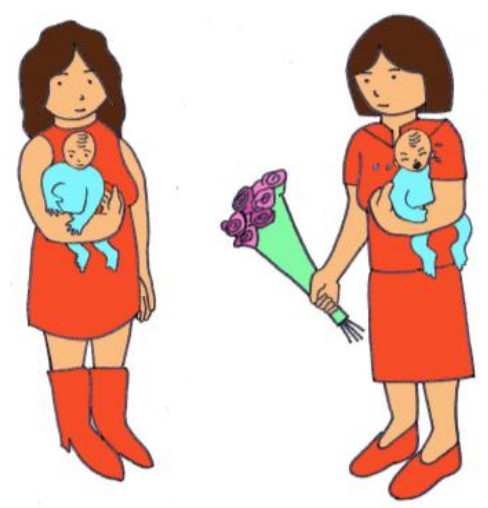

Le bébé avec la femme avec des fleurs.

the baby with the woman with some flowers

'The baby with the woman with the flowers.'

16. Recursive locative condition (RDM)

La brosse dans le pot sur la tablette.

the toothbrush in the cup on the shelf

'The toothbrush in the cup on the shelf.'

17. Non-recursive condition (locative or a combination of locative and comitative) (SDM)

Les livres dans la boite sous la chaise

The books inside the box under the chair

'The books in the box (and) under the chair.'

18. Recursive possessive condition (RDM)

$\begin{array}{llllll}\text { Le ballon de la sour } & \text { d' } & \text { Elmo. } \\ \text { the ball of the sister } & \text { of } & \text { Elmo } \\ \text { 'Elmo's sister's ball.' } & & & & \end{array}$

19. Recursive relational noun condition (RDM)

Sur la pile de peintures de fleurs.

on the pile of paintings of flowers

'On the pile of paintings of flowers.'

Items were presented as an illustrated booklet with semi-randomized orders. Participants were randomly assigned to two versions with different orderings. The first three items were training distractors.

As was the case in the original English experiment, if during the test a participant did not give a complete answer after the first attempt, the experimenter was instructed to repeat the prompt two additional times. If a child was pointing a response, he or she would be invited to describe the picture with words. For incomplete answer (e.g., "The books" instead of "The books in the box under the chair"), the experimenter would invite clarification (e.g., "Yes, you are right, but which one?").

\subsection{Coding}

To analyze French results, we adapted the English coding system developed in Pérez-Leroux et al. (2012) and Pérez-Leroux et al. (2015), which includes syntactic and semantic 
classifications. The syntactic coding characterizes the response based on level of embedding and syntactic devices used to link embedded phrases. The level of embedding was analyzed as Single (a single NP; 20a), Level 1 (a noun modified by a single embedded phrase; 20b), or Level 2 (a noun modified by two embedded phrases; 20c):

20. Syntactic Coding

a. Single:

[DP le ballon]

the ball

'The ball.'

b. Level 1:

$\begin{array}{llll}\text { [DP le ballon [PP } & \text { de } & \text { la } & \text { soeur] } \\ \text { the ball } & \text { of the } & \text { sister }\end{array}$

'The sister's ball.'

c. Level 2:

$\begin{array}{lllll}{[\mathrm{DP}} & \begin{array}{l}\text { le ballon } \\ \text { the ball }\end{array} & \begin{array}{l}\text { de la soeur } \\ \text { of the sister }\end{array} & \begin{array}{ll}{[\mathrm{PP}} & \mathrm{d}^{\prime} \text { Elmo } \\ \text { of Elmo }\end{array}\end{array}$

'Elmo's sister's ball'

Recursive phrases containing two embedded phrases were classified as Level 2 (cf. 20c). Non-recursive doubly modified structures, such as (17) with the relevant part of the structure given in (21), were classified as 2 Level 1 since both PPs modify the higher N.

21. [DP Les livres [PP dans la boite] [PP sous la chaise]]

'The books in the box under the chair.'

We also coded the syntactic mechanisms employed to integrate the modifiers. Embedding linking strategies included PPs (22a), RCs (22b) or a combination of both (Mixed, 22c).

22. Syntactic linking strategies

a. Prepositional phrases:

$\begin{array}{llll}{[\mathrm{DP}} & \begin{array}{l}\text { Le ballon } \\ \text { the ball }\end{array}\end{array} \quad \begin{array}{ll}\text { [PP } & \begin{array}{l}\text { de la soeur } \\ \text { of the sister }\end{array}\end{array} \quad \begin{aligned} & \text { à Elmol] } \\ & \text { of Elmo }\end{aligned}$

'Elmo's sister's ball.' $\quad(6 ; 6)(\mathrm{PP}-\mathrm{PP})$

b. Relative clauses:

[DP Celui [RC qui est dans les bras de la femme [RC qui a un bouquet de fleurs]]] the one who is in the arms of the woman who has a bouquet of flowers

'The one who is in the arms of the woman who has a bouquet of flowers.' (6;5) (RC-RC)

c. Mixed:

[DP La brosse à dents [RC qui est située dans un verre [PP sur la tablette orange]]] the toothbrush that is situated in the cup on the shelf orange.

'The toothbrush that is in the cup on the orange shelf.'

(Adult) (RC-PP)

Participants also employed other linking strategies, which do not result in phrasal embedding, such as clausal or predicative relation (23a), coordination (23b), apposition (23c), compounds (23d). Utterances containing such linking strategies were not analyzed as targets. 
23. Other linking strategies (without embedding)

a. Clausal relation:

Le chien il est là

$$
\text { pis il va manger ce }
$$

and he is going

the dog he is there

to eat

'The dog he's there, and he is going to eat this hot dog.'

b. Coordination:

Le ballon d'Elmo et de sa sœur.

the ball of Elmo and of his sister

'Elmo's and his sister's ball.'

c. Apposition:

Lui [le ballon], la soeur de Nemo [Elmo]

it [the ball] the sister of Elmo

'It, Elmo's sister.'

d. Compound:

La sœur grenouille

the sister frog

'The sister frog.'

A second step in coding integrated the syntactic coding with an assessment of whether the participant's response succeeded in identifying the target referent. The semantic coding takes into consideration whether the target head noun and modifiers were included in the response, and how they were integrated. The various types of responses identified included incomplete responses (24a), which did not provide sufficient modifiers to disambiguate the target referent, and sequential responses, such as (24b), which identified the referent but across multiple utterances. Alternative responses (24c) were also structurally simpler, and relied in other property of the visual scenario to describe the target, primarily using spatial terms. Finally, responses that included all three descriptors (the head noun, and the two target modifiers) in a single utterance, were classified as non-embedded (24d), or target (15)-(19) responses, depending on the types of linking strategies employed.

\section{Semantic Coding}

a. Incomplete responses: single nominal or Level 1 NPs

Le ballon
the ball

'The ball.'

b. Sequential responses: a sequence of single nominals or Level 1 responses that identified all the relevant referential relations, but not in a single utterance le ballon de la soeur. La soeur d'Elmo. 'Sister's ball. Elmo's sister.' 
c. Alternative responses: referentially correct, but without the target modifiers

Celui [le ballon] à droite.

the one [the ball] to right

'The one to the right.'

d. Non-embedded responses: referentially complete, but without recursively embedded modification

Le ballon d'Elmo et de sa soeur.

The ball of Elmo and of his sister

'Elmo's and his sister's ball.'

Only responses which involved both recursive modification of an NP and correct identification of the appropriate referent (i.e., responses that were referentially successful) were considered target in the recursive conditions. The results were coded by one investigator and then independently verified by a second investigator.

\section{Results}

Our results provide the following answers to our research questions. We return to our hypothesis in Section 5.

\subsection{General Characteristics of the French Recursive Noun Phrases: French-Speaking Children vs. Adults}

What are the main patterns of production in French-speaking children compared to adults? As shown in Figure 1, adults produced between half and two-thirds of the target responses across conditions. Their highest rates of targets are in the possessive and the non-recursive conditions, followed by the comitatives. The condition that elicited the least targets was the relational noun condition. As for the French speaking children, rates of target responses (averaged across all conditions, RDM and SDM) centered around 16,24 , and $28 \%$ for four-, five-, and six-year-olds, respectively. The general distribution of targets across conditions was similar, with older children performing better with comitatives than the other conditions. Since the goal of this paper is to focus on the onset of recursive modification, we do not discuss the non-recursive condition further but see Pérez-Leroux et al. (forthcoming), for extensive discussion.

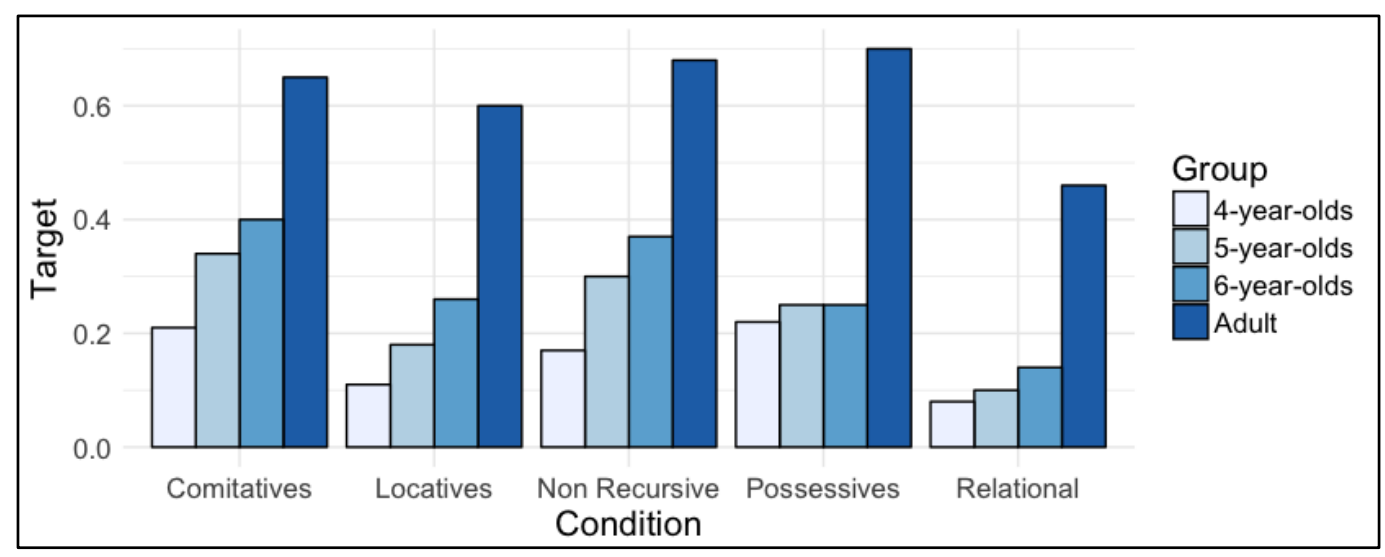

Figure 1. Proportion of target responses across conditions in French-speaking children and adults.

Individually, while some younger children produced no recursive responses, only 8 out of 26 children in the four-year-old group and 3 out of the 26 children in five-year-old group did not produce any recursive targets. In contrast, all of the French six-year-olds produced recursive responses. 
The kinds of errors produced by children and adults can be seen in Table 1, which reports the distribution of response types for the four recursive conditions, according to the semantic coding.

Table 1. Composition of response type to recursive conditions, represented as number of tokens (\% in parenthesis).

\begin{tabular}{|c|c|c|c|c|c|c|c|c|c|c|}
\hline \multirow{2}{*}{$\begin{array}{c}\text { Group } \\
\text { Four-year-olds }\end{array}$} & \multicolumn{2}{|c|}{ Incomplete } & \multicolumn{2}{|c|}{ Sequential } & \multicolumn{2}{|c|}{ Alternative } & \multicolumn{2}{|c|}{ Non-Embedded } & \multicolumn{2}{|c|}{ Target } \\
\hline & 353 & $(61 \%)$ & 36 & $(6 \%)$ & 63 & $(11 \%)$ & 38 & $(7 \%)$ & 93 & $(16 \%)$ \\
\hline Five-year-olds & 188 & $(31 \%)$ & 139 & $(23 \%)$ & 78 & $(13 \%)$ & 60 & $(10 \%)$ & 132 & $(22 \%)$ \\
\hline Six-year-olds & 199 & $(32 \%)$ & 138 & $(22 \%)$ & 61 & $(10 \%)$ & 55 & $(9 \%)$ & 162 & $(26 \%)$ \\
\hline Adults & 21 & $(7 \%)$ & 12 & $(4 \%)$ & 30 & $(10 \%)$ & 50 & $(17 \%)$ & 175 & $(61 \%)$ \\
\hline
\end{tabular}

For adults, the primary non-target pattern corresponds to complete responses that involved the use of non-embedding strategies such as turning a PP modifier into an adjective, apposition, and clausal relations (e.g., (25)), followed by alternative responses (e.g., (26)).

25. Target:

$$
\begin{aligned}
& \text { Le sac à dos de l' ami de Dora. } \\
& \text { the backpack of the friend of Dora } \\
& \text { 'Dora's friend's backpack.' }
\end{aligned}
$$

$\begin{array}{llll}\text { Clausal relations: } & \begin{array}{l}\text { Le sac à dos bleu est porté par l' ami de Dora. } \\ \text { the backpack blue is carried by the friend } \\ \text { 'The blue backpack is carried by Dora's friend. }\end{array}\end{array}$

(Adult)

26. Target:
Le chien sous
la table près de la fenêtre.
the dog under
thetable near of the window
'The dog under the table near the window.'

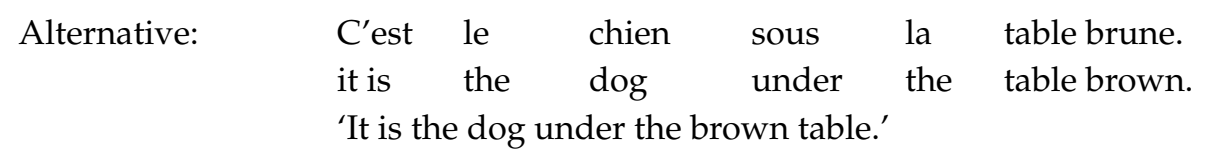

(Adult)

For children, in contrast, incomplete responses are the primary error pattern overall; they prefer to produce structures with only one level of embedding. For the four-year-olds, these represent more than half of the responses. We observe a developmental shift whereby the older children tend to produce less incomplete responses, and increase the numbers of targets and sequential responses produced, in comparison to their younger counterparts.

\subsection{Comparing the Frequency of Recursive Responses in French and English}

\subsubsection{Overall Rates of Recursive Responses in Children and Adults}

As shown in Figure 2, there are no great differences between the languages. We analyzed the data using the glmer function in the statistical package lme4 in R. We entered the data into a generalized linear mixed model fit by maximum likelihood method (Laplace Approximation), using the binomial distribution. The dependent variable was whether the responses were target (i.e., recursive or not), with group (adult vs. children) and language (French vs. English) as fixed effects, and participant as a random effect. Neither language nor the interaction between language and group was significant. The effect of the group was highly significant $(\beta=-1.903, \mathrm{SE}=0.318, p<0.001)$. 


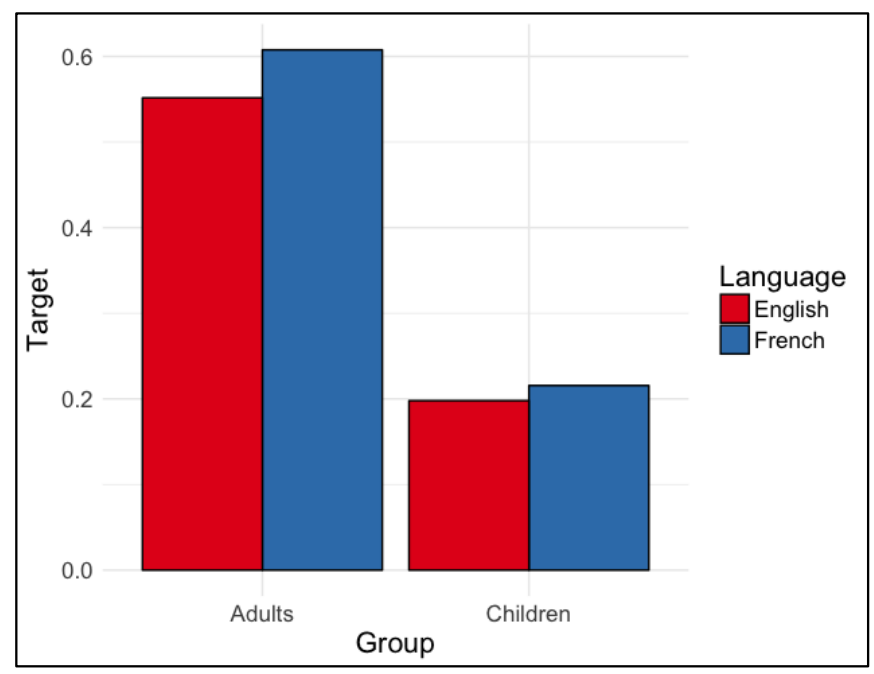

Figure 2. Average proportion of overall target responses across recursive conditions comparing English and French-speaking children and adults.

\subsubsection{An Initial French Advantage?}

To test the possibility of an early language difference, we then considered only the children's data. The scatterplot in Figure 3 represents individual participants distributed by age and proportion of target responses produced, separated by language. Figure 3 shows the general developmental trend, and a great degree of overlap in the two languages. We entered a second model for analysis, using the same parameters as in the first model, with the only difference that the group factor was replaced with the three age groups in children (four-, five- and six-year-olds).

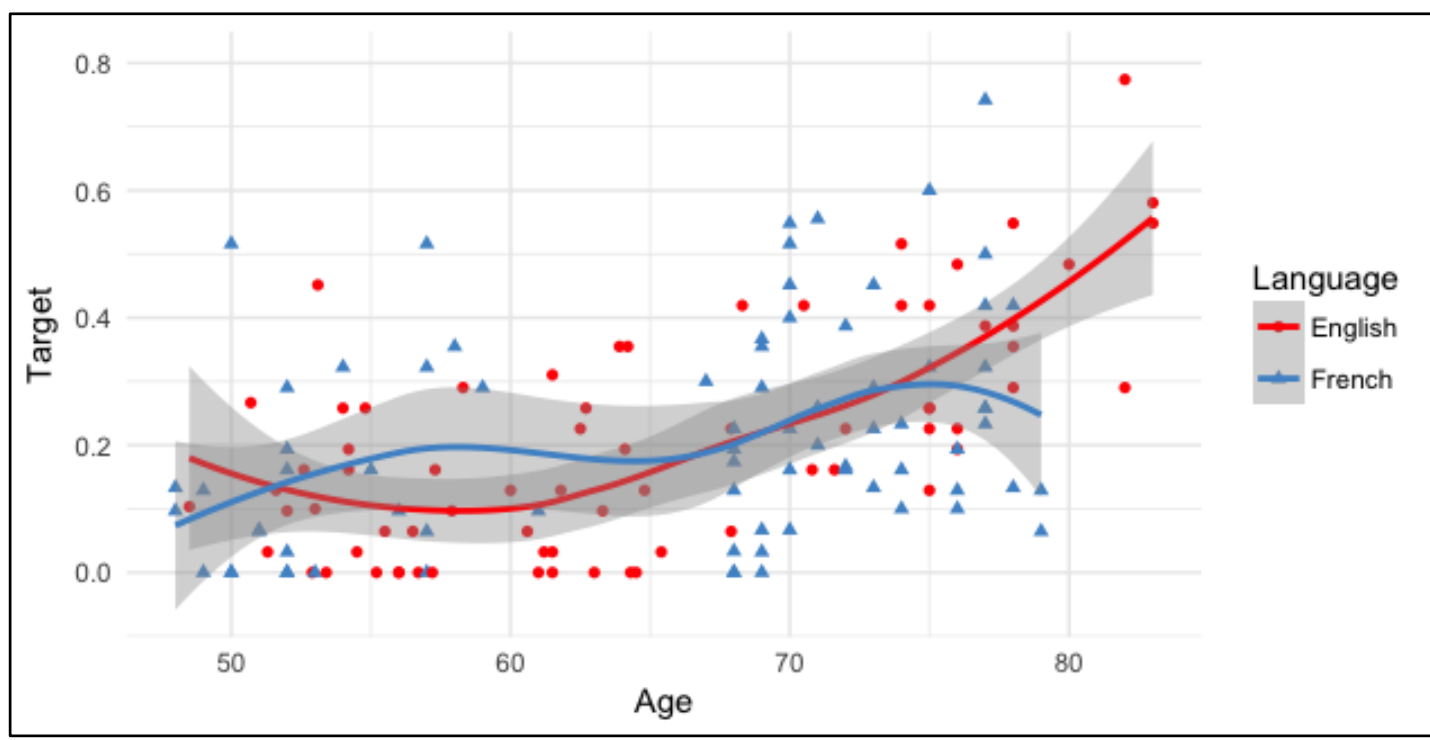

Figure 3. Individual children plotted as a function of age (in months) and proportion of target recursive responses produced, separated by language. A locally weighted smoothed line (lowess) is fitted for each language. Associated shaded areas indicate 95\% confidence interval.

Again, this second model indicates no significant effect of language nor language by age group interaction. The effect of age was significant for six-year-olds. As shown in Figure 3, no child after 70 months failed to produce RDM responses, so that the rates of target responses in the older children is overall higher. 
Finally, we focused the contrasts for the effect of language for each age group. This was important since the trends vary for each period. A Wilcoxon test of differences on the effect of language for four-year-olds is not significant $(\mathrm{W}=305, p=0.715$ ). This is similarly true for the five-year-old group $(\mathrm{W}=245, p=0.135)$.

\subsubsection{A French Possessive Advantage?}

Our last question concerned the possibility of identifying a local French advantage for possessives. As we have seen, French possessives follow the regular right branching pattern, whereas possession in English is primarily expressed via a left-branching strategy, the Saxon genitive '-'s', in contrast to the right-branching patterns that dominate English clausal and nominal structures. Table 2 shows that the patterns of development for the possessive contexts are similar to the overall results described in Section 4.2.1, in that there is a small initial advantage for French children (4\%-5\%), but by age six, the comparison group of English-speaking children actually become more productive than the French children.

Table 2. Mean proportion of target responses to the possessive condition across groups, by language.

\begin{tabular}{ccc}
\hline Group & English & French \\
\hline Four-year-olds & 0.18 & 0.22 \\
Five-year-olds & 0.20 & 0.25 \\
Six-year-olds & 0.44 & 0.25 \\
Adults & 0.72 & 0.70 \\
\hline
\end{tabular}

As before, we tested the language contrast by mean of a Wilcoxon test of differences. The results indicate that the effect of language is not significant, neither for the four-year-olds ( $W=305, p=0.715$ ), nor for the five-year-olds $(\mathrm{W}=291, p=0.531)$.

\subsubsection{A Difference in Types of Strategies Employed?}

We next compared another potential source of differences between the two languages: the relative number of pure PP responses vs. mix of RCs and PPs. Associated work on the English data (Pérez-Leroux et al. forthcoming) noted the use of RC and mixed responses. These patterns were deemed surprising since the materials were designed to elicit simpler PP structures. Even more surprising was the fact that English-speaking children produced as many RCs as adults, given a broad literature suggesting that RCs are complex and delayed in acquisition. Furthermore, English-speaking children specifically produced more RC responses in the recursive condition. In French, where PPs are required in possessive contexts, we expected the PP responses to dominate in general. The examples in (27) and (28) illustrate the responses discussed here for both languages:

27. French

a. Prepositional phrases:

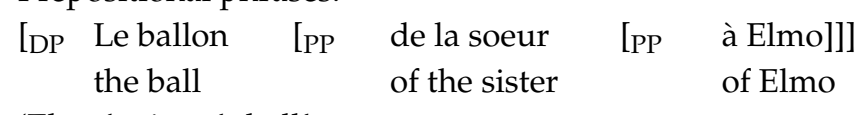

'Elmo's sister's ball'

(6;6) (PP-PP)

b. Mixed structures:
[DP La brosse à dents $\quad[R C$
qui est située dans un verre the toothbrush
that is situated in a cup
[PP sur la tablette orange]]] on the shelf orange

'The toothbrush that is in the cup on the orange shelf.' 
c. Relative clauses:

[DP Celui [RC qui est dans les bras de la femme [RC qui a un bouquet de fleurs]]] the one that is in the arms of the woman who has a bouquet of flowers

'The one who is in the arms of the woman who has a bouquet of flowers.'

$(6 ; 5)($ RC-RC)

28. English

a. Prepositional phrases:

The girl with the hat ... the one with the dog with the hat

b. Mixed structures:

The one with the dog that has a hat.

c. Relative clauses:

The chick that's on the croc'dile that's on in the water.

For the current analysis, we considered only the conditions which had recursive PPs as targets, that is the comitative, locative, and relational noun condition, to the exclusion of the possessive condition. We further excluded 11 English tokens where a possessive was used in the relational noun condition. Most of these were produced by adults and six-year-olds.

The percentage of responses classified as PP/Mixed/RCs per age group is shown in Figures 4 and 5. In both language groups the most common alternative to PPs is mixing PPs and RCs. Figure 4 shows how English-speaking children use as many RC and combined RC and PP as adults. This contrasts with French-speaking children, who rely primarily on PPs. At age six, we observe a trend towards the adult pattern, so the relative proportion of PP responses decreases and RC and Mixed responses increase.

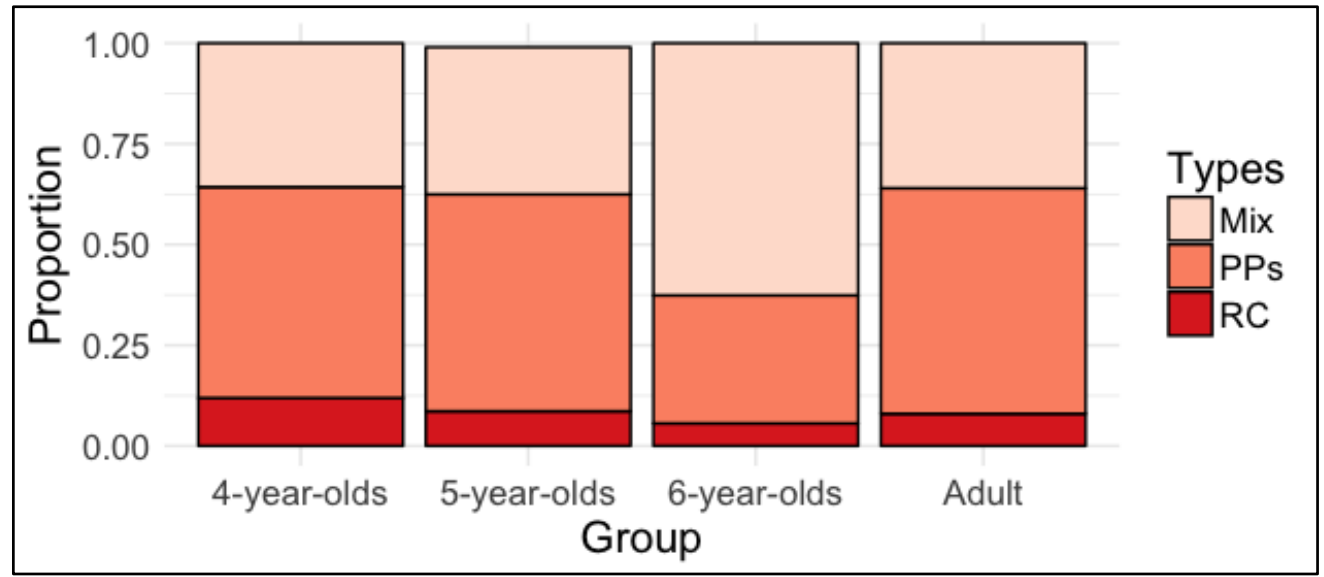

Figure 4. Composition of types of target responses across age groups in English. PP: Prepositional Phrase; RC: relative clauses; Mix: combination of PP and RC. 


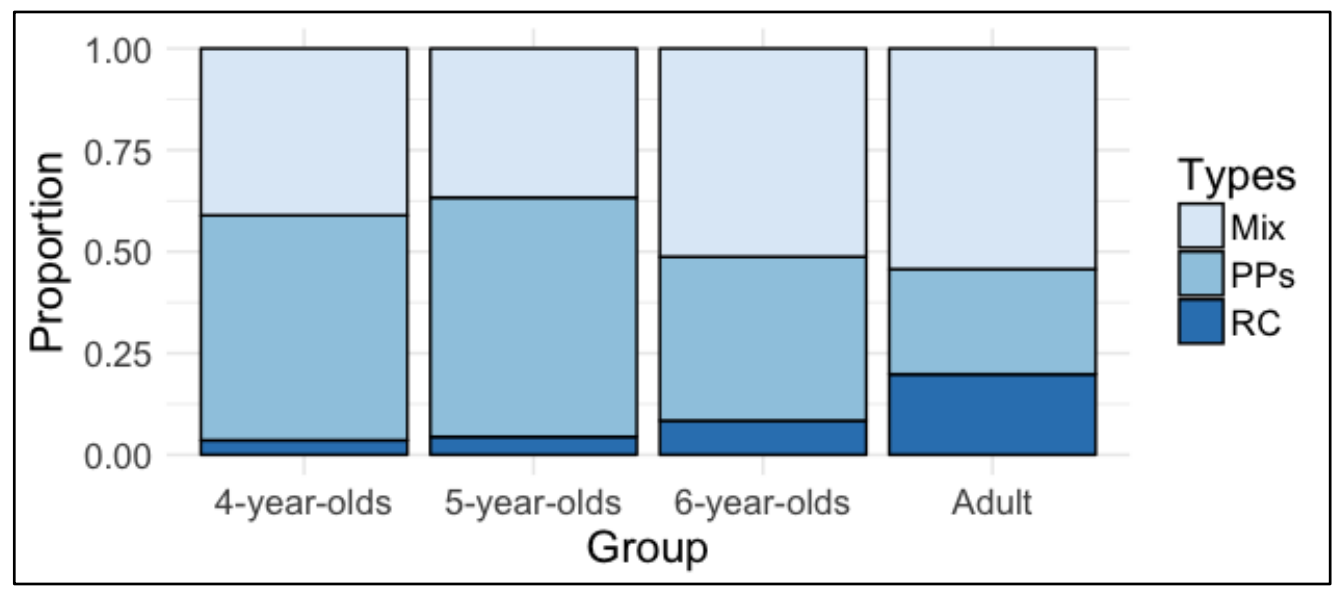

Figure 5. Composition of types of target responses across age groups in French.

Contrary to our expectations, PPs do not generally dominate in the adult data. Somehow, PP use in French adults and older children appears more restricted than in English.

The data on response type was entered into a generalized linear mixed model fit by maximum likelihood method (Laplace Approximation), using the binomial distribution. The dependent variable was whether the recursive responses consisted solely of PPs or not, with group (adult vs. children) and language (French vs. English) as fixed effects, and participant as a random effect. There is an effect of language $(\beta=-1.658, \mathrm{SE}=0.541, p=0.002)$, but no effect of group $(\beta=-0.689, \mathrm{SE}=0.441$, $p=0.117)$. The French-speaking children produced more PP responses than other groups, giving rise to a significant interaction between language and group $(\beta=1.975, \mathrm{SE}=0.618, p=0.001)$.

\section{Discussion}

We started from a series of simple questions. Focusing on the age where it has been shown that recursive modification is acquired in other languages, question I was primarily developmental: How do preschool children differ from French-speaking adults in their production of complex, recursively modified DPs? As we summarized in Section 2.3, existing characterizations of development in this domain speaks mostly about the emergence and productivity of simple modification. Other than data on double adjective use, and on types of relative clauses children use, the continued growth of complexity in the French DP is mostly undocumented. Our data show that between the ages of four and six, French-speaking children start by primarily producing structurally simpler responses (the incomplete and sequential patterns). The number of target responses produced gradually increases, without yet reaching adult levels. In terms of types of embedded responses, adults differ from children in showing a preference for RCs, and Mixed modifiers (RCs and PPs). In contrast, two thirds of the target responses of the younger groups of French-speaking children were PP-only.

The remaining questions in Section 1 address our main hypothesis: Can specific characteristics of a language set limits on children's ability to develop recursive modification? In this case, our data showed no general advantage for French during the preschool-early school age periods, which is when recursive modification emerges and becomes productive (Questions II and III). Nor was there a specific advantage for possession (Question IV). We observed slightly increased production in the four-year-old range, but this was not significant.

Given that we found no difference in the general developmental patterns of complex NPs in French and English-speaking children, we can maintain the Null Hypothesis and conclude that recursion is equally difficult across languages. Admittedly, a comparison of only two languages, which are also very close typologically, is not sufficient to conclude without a doubt that this will be true for any and all pairs of languages. Nevertheless, for the present, we find no evidence in support of the Alternative Hypothesis. 
This does not exclude the possibility that typological differences can have an effect on development and this is where the strategies discussed in Section 4.2.4 become relevant. First, the differences we report between French and English participants demonstrate that our method not only elicits the targeted structures but is also robust enough to be sensitive to potential typological differences between the two languages. Although we cannot answer this question for the moment, we can ask why PPs are significantly more disfavored in French than in English-speaking adults. Our results thus point to important differences between the behavior of French and English-speaking adults but, given the dearth of studies on RDM and SDM constructions in the two languages, we are not in a position to elaborate on this at this stage.

Returning to the general patterns, we find that RDM is challenging for all groups but more so for children compared to adults, in both languages. If RDM corresponds to Merge and Merge is strongly anchored in Universal Grammar then what is challenging about it? The narrow syntax component of the derivation of RDM constructions cannot be the locus of the difficulty, so we must turn to the interface components and processing considerations to account for the results. Further research is required to identify the specific challenges that children must overcome as part of their development. One potential source is suggested by recent work on working memory and its interaction with the development of recursion in the thought domain. The research question examined in Arslan et al. (2017) is strikingly similar to ours, although it targets a different domain: "Why do children need some years to pass second-order false belief tasks once they are able to pass first-order false belief?" (p. 2). They also consider a complexity account according to which the number of beliefs involved and the recursive organization of second-order theory of mind stories adds further demands on working memory. For them, working memory acts as a "bottleneck" on the serialization task needed to process the nested structures involved. Could a similar "serial processing bottleneck" (Verbrugge 2009) be invoked in our domain to account for both the difficulty with and the development of multiple recursive embedding, specifically in the cases involving multiple PPs? Could it be the case that the RC and Mixed RC + PP strategies are used by our participants to facilitate the serialization of the recursive structure? While we cannot address these questions here, our results are in line with "the attempt to account for properties of language in terms of general considerations of computational efficiency, eliminating some of the technology postulated as specific to language and providing more principled explanation of linguistic phenomena" (Chomsky 2005, p. 1). Chomsky refers to these considerations not specific to language as one of the factors (the third factor) contributing to the growth of language in humans. In our particular study, this perspective allows us to maintain a simple and universal Merge operation and to impute the difficulties observed in its applications to processing demands that apply in other domains of human cognition. In other words, there is no need to include additional mechanisms in the phrase structure building rules to account for our results. Our findings may thus contribute to a better understanding of how universal properties of language interact with third factor considerations in shaping the acquisition path.

Acknowledgments: Funding for this research was provide by a Social Sciences and Humanities Research Council Insight Grant (435-2014-2000 Development of NP complexity in children). Thanks to Mélanie Elliott for help with data collection; to Patrick Thériault and Jeanne Mathieu-Lessard for help with translations and recruitment of participants in Quebec City as well as to the participants, parents, and teachers. We also thank the members of the Recursion and Complexity research group, Diane Massam, Susana Bejar, and Petra Schulz for their comments and/or suggestions.

Author Contributions: Roberge, Pérez-Leroux, and Frolova conceived and designed the experiment; Frolova performed the experiments; Pérez-Leroux and Frolova analyzed the data; Roberge, Pérez-Leroux, and Frolova wrote the paper.

Conflicts of Interest: The authors declare no conflict of interest. The funding sponsors had no role in the design of the study; in the collection, analyses, or interpretation of data; in the writing of the manuscript, or in the decision to publish the results. 


\section{References}

Abeillé, Anne, Bonami Olivier, Godar Danièle, and Jesse Tseng. 2003. The syntax of French à and de: An HPSG analysis. In Computational Linguistics Dimensions of the Syntax and Semantics Prepositions. Edited by Patrick Saint-Dizier. Dordrecht: Springer, pp. 147-62.

Aimard, Paule. 1996. Les débuts du langage chez l'enfant. Paris: DUNOD, ISBN 2100028901.

Arslan, Burcu, Hohenberger Annette, and Rineke Verbugge. 2017. Syntactic cecursion facilitates and working memory predicts recursive theory of mind. PLOS ONE 12: e0169510. [CrossRef] [PubMed]

Bassano, Dominique, Maillochon Isabelle, and Sylvain Mottet. 2008. Noun grammaticalization and determiner use in French children's speech: A gradual development with prosodic and lexical influences. Journal of Child Language 35: 403-38. [CrossRef] [PubMed]

Bejar, Susana, Massam Diane, Pérez-Leroux Ana-Teresa, and Yves Roberge. Forthcoming. Rethinking complexity. Unpublished manuscript. Toronto, ON, Canada: University of Toronto.

Belzil, Isabelle. 2004. L'absence de Relatives Obliques Standard Chez les Enfants Francophones: Variation et Théorie Syntaxique. Manuscript. Kingston, ON, Canada: Queen's University. Available online: http:/ / cognitio.uqam.ca/2004/belzil.pdf (accessed on 19 December 2017).

Bouvier, Nadine, and Françoise Platone. 1976. Étude génétique de la construction d'une détermination linguistique complexe: L'expression d'un même contenu par des enfants d'âges différents. Cahiers du CRESAS 16A. Paris: Institut Pédagogique National.

Chomsky, Noam. 1995. The Minimalist Program. Cambridge: The MIT Press. ISBN 0262032295.

Chomsky, Noam. 2005. Three factors in language design. Linguistic Inquiry 36: 1-22. [CrossRef]

Clark, Eve. 1986. Acquisition of romance, with special reference to French. In The Crosslinguistic Study of Language Acquisition: The Data. Edited by Dan Isaac Slobin. Erlbaum: Hillsdale, vol. 1, pp. 687-782. ISBN 0898593670.

Culicover, Peter W. 2013. Grammar and Complexity: Language at the Intersection of Competence and Performance. Oxford: Oxford University Press: ISBN 0199654603.

Culicover, Peter W., and Ray Jackendoff. 2006. The simpler syntax hypothesis. Trends in Cognitive Sciences 10: 413-18. [CrossRef] [PubMed]

Demuth, Katherine, and Annie Tremblay. 2008. Prosodically-conditioned variability in children's production of French determiners. Journal of Child Language 35: 99-127. [CrossRef] [PubMed]

Eisenberg, Sarita, Ukrainetz Teresa, Hsu Jennifer, Kaderavek Joan, Justice Laura, and Ronald Gillam. 2008. Noun phrase elaboration in children's spoken stories. Language, Speech, and Hearing Services in Schools 39: 145-57. [CrossRef]

Evans, Nicholas, and Stephen C. Levinson. 2009. The myth of language universals. Behavioral and Brain Sciences 32: 429-92. [CrossRef] [PubMed]

Fragman, Cathy. 1998. Les propriétés distinctives de la syntaxe enfantine et le développement des relatives en français. Ph.D. dissertation, Université de Montréal, Montreal, QC, Canada.

Frechette, Roseline, and Marie Labelle. 2007. Influence of prosody on the production of determiners and adjectives in two-year-old children's sentences. In BUCLD 32. Edited by Harvey Chan, Heather Jacob and Enkeleida Kapia. Somerville: Cascadilla Press, pp. 132-42. ISBN 978-1-57473-084-5.

Givón, Thomas. 2009. The Genesis of Syntactic Complexity. Amsterdam: John Benjamins. [CrossRef]

Godard, Danièle. 1988. La Syntaxe des relatives en français. Paris: CNRS, ISBN 222204166X.

Goldin-Meadow, Susan. 1982. The resilience of recursion: A study of a communication system developed without a conventional language model. In Language Acquisition: The State of the Art. Edited by Eric Wanner and Lila R. Gleitman. New York: Cambridge University Press, pp. 51-77. ISBN 0521282381.

Jisa, Harriet, and Sophie Kern. 1998. Relative clauses in French children's narrative texts. Journal of Child Language 25: 623-52. [CrossRef] [PubMed]

Labelle, Marie. 1990. WH-movement, and the development of relative clauses. Language Acquisition 1: 95-119. [CrossRef]

Laenzlinger, Christopher. 2005. French adjective ordering: perspectives on DP-internal movement types. Lingua 115: 645-89. [CrossRef]

Limbach, Maxi, and Dani Adone. 2010. Language acquisition of recursive possessives in English. In BUCLD 34. Edited by Katie Franich, Kate M. Iserman and Lauren L. Keil. Somerville: Cascadilla Press, pp. 281-90. ISBN 9781574731552. 
McWhorter, John H. 2011. Linguistic Simplicity and Complexity: Why Do Languages Undress? Berlin: Walter de Gruyter, ISBN 1934078379.

Newmeyer, Frederick J., and Laurel B. Preston. 2014. Measuring Grammatical Complexity. Oxford: Oxford University Press, ISBN 0199685304.

Pannemann, Maren. 2007. DP Acquisition as Structure Unravelling. Ph.D. dissertation, University of Amsterdam, Amsterdam, The Netherlands. Available online: https:/ / www.lotpublications.nl/Documents/167_fulltext.pdf (accessed on 16 December 2017).

Pérez-Leroux, Ana Teresa, Castilla-Earls Anny, Bejar Susana, and Diane Massam. 2012. Elmo's sister's ball: The problem of acquiring nominal recursion. Language Acquisition 19: 301-11. [CrossRef]

Pérez-Leroux, Ana Teresa, Castilla-Earls Anny, Bejar Susana, Massam Diane, and Tyler Peterson. 2015. Strong continuity and children's development of DP recursion. In Recursion in Brazilian Languages and beyond. Edited by Maia Marcus, Andrew Nevins and Luiz Amaral. Cambridge: Cambridge University Press, pp. 182-200.

Pérez-Leroux, Ana Teresa, Pettibone Erin, and Anny Castilla-Earls. 2017. Down two steps: Are bilinguals delayed in the acquisition of recursively embedded PPs? Matraga 24: 393-416. [CrossRef]

Pérez-Leroux, Ana Teresa, Peterson Tyler, Castilla-Earls Anny, Bejar Susana, Massam Diane, and Yves Roberge. Forthcoming. Recursion and the acquisition of complex NPs. Language.

Prévost, Philippe. 2009. The Acquisition of French: The Development of Inflectional Morphology and Syntax in L1 Acquisition, Bilingualism, and L2 Acquisition. Amsterdam and Philadelphia: John Benjamins, ISBN 9027253129.

Roeper, Thomas. 2011. The acquisition of recursion: How formalism articulates the child's path. Biolinguistics 5: $57-86$.

Roeper, Thomas, and William Snyder. 2004. Recursion as an analytic device in acquisition. In Proceedings of GALA 2003 (Generative Approaches to Language Acquisition). Edited by Jacqueline van Kampen and Sergio Baauw. Utrecht: LOT Publications, pp. 401-8.

Roeper, Thomas, and Margaret Speas. 2014. Recursion: Complexity in Cognition. Dordrecht: Springer, ISBN 9783319050850.

Royle, Phaedra, and Isabelle Stine. 2012. The French noun phrase in preschool children with SLI: morphosyntactic and error analyses. Journal of Child Language 40: 945-70. [CrossRef] [PubMed]

Royle, Phaedra, and Daniel Valois. 2010. Acquisition of adjectives in Quebec French as revealed by elicitation data. French Language Studies 20: 313-38. [CrossRef]

Trotzke, Andreas, and Josef Bayer. 2015. Syntactic Complexity across Interfaces. Berlin: Walter de Gruyter, ISBN 978-1-61451-790-0.

Trotzke, Andreas, and Jan-Wouter Zwart. 2014. The complexity of narrow syntax: Minimalism, representational economy, and simplest Merge. In Measuring Grammatical Complexity. Edited by Frederick J. Newmeyer and Laurel B. Preston. Oxford: Oxford University Press, pp. 128-47. ISBN 0199685304.

Valois, Daniel, and Phaedre Royle. 2009. Partitivity, atomization, and noun-drop: A longitudinal study of French child language. Language Acquisition 16: 82-105. [CrossRef]

Vandeloise, Claude. 1991. Spatial Prepositions: A Case Study from French. Chicago: University of Chicago Press, ISBN 0226847276.

Verbrugge, Rineke. 2009. Logic and social cognition: The facts matter, and so do computational models. Journal of Philosophical Logic 38: 649-80. [CrossRef]

Vercollier, Alain, Vercollier Claudine, and Kay Bourlier. 2004. Difficultés expliquées du français ... for English Speakers. Tours: CLE International, ISBN 978 209-033701-3.

Watumull, Jeffrey, Hauser Marc D., Roberts Ian G., and Norbert Hornstein. 2014. On recursion. Frontiers in Psychology 4: 1-7. [CrossRef] [PubMed]

(C) 2018 by the authors. Licensee MDPI, Basel, Switzerland. This article is an open access article distributed under the terms and conditions of the Creative Commons Attribution (CC BY) license (http:/ / creativecommons.org/licenses/by/4.0/). 